\title{
A cárie precoce na infância ou cárie de primeira infância: uma revisão narrativa
}

\author{
Early child hood caries or early child hood caries: a narrative review \\ Caries de la primera infância o caries de la primera infancia: una revisión narrativa
}

Recebido: 21/10/2021 | Revisado: 28/10/2021 | Aceito: 29/10/2021 | Publicado: 01/11/2021

\author{
Andressa Lara Braga Bernardes \\ ORCID: https://orcid.org/0000-0002-7970-4451 \\ Faculdade Patos de Minas, Brasil \\ E-mail: Andressa.06505@alunofpm.com.br \\ Lia Dietrich \\ ORCID: https://orcid.org/0000-0001-7887-8591 \\ E-mail: lia.dietrich@ufvjm.edu.br \\ Mayra Maria Coury de França \\ ORCID: https://orcid.org/0000-0002-9395-6823 \\ Faculdade Patos de Minas, Brasil \\ E-mail: mayra.franca@faculdadepatosdeminas.edu.br
}

Universidade Federal dos Vales do Jequitinhonha e Mucuri, Brasil

\begin{abstract}
Resumo
A Cárie precoce na infância ou Cárie da Primeira Infância (CPI) é uma doença multifatorial de progressão rápida e severa. Ocorre durante a primeira infância e é influenciada principalmente pela microbiota e a dieta cariogênica. Vários tratamentos são propostos, a depender da extensão das lesões cariosas, variam desde a aplicação tópica de flúor até tratamentos mais invasivos, como exodontia e reabilitação ortodôntica. É uma doença que acomete pacientes menos favorecidos atingindo estágios severos quando não tratada, tem etiologia desconhecida pelos pais onde não percebem o desenvolvimento dos primeiros sinais clínicos, buscando atendimento odontológico tardio quando o paciente apresenta dor e desconforto na mastigação do lado afetado. Tem-se notado que a CPI apresenta percussões que afeta a qualidade de vida e podem comprometer no crescimento e desenvolvimento da criança. A cárie é contudo uma doença evitável a partir do momento em que os fatores que a levam ao seu desenvolvimento se tornem conhecidos. Hábitos alimentares inadequados são os principais fatores de riscos, a alimentação do hospedeiro pode ser vista como fator primário de determinação da susceptibilidade para a doença. Conclui-se que a cárie dentária (CD) é uma deterioração do dente fortemente influenciada pelo estilo de vida do indivíduo.
\end{abstract}

Palavras-chave: Cárie dentaria; Infância; Cárie precoce.

\begin{abstract}
Early childhood caries or Early Childhood Caries (CPI) is a multifactorial disease with rapid and severe progression. It occurs during early childhood and is mainly influenced by the microbiota and cariogenic diet. Several treatments are proposed, depending on the extent of the carious lesions, ranging from the topical application of fluoride to more invasive treatments, such as tooth extraction and orthodontic rehabilitation. It is a disease that affects underprivileged patients reaching severe stages when untreated, has unknown etiology by parents where they do not notice the development of the first clinical signs, seeking late dental care when the patient has pain and discomfort in chewing on the affected side. It has been noted that CPI has percussions that affect the quality of life and can compromise the child's growth and development. Caries is, however, a preventable disease once the factors that lead to its development become known. Inadequate eating habits are the main risk factors, the host's diet can be seen as the primary factor in determining susceptibility to the disease. It is concluded that dental caries (CD) is a tooth deterioration strongly influenced by the individual's lifestyle.
\end{abstract}

Keywords: Dental caries; Childhood; Early caries.

\section{Resumen}

La caries de la primera infancia o caries de la primera infancia (CPI) es una enfermedad multifactorial de progresión rápida y grave. Ocurre durante la primera infancia y está influenciada principalmente por la microbiota y la dieta cariogénica. Se proponen varios tratamientos, dependiendo de la extensión de las lesiones cariosas, que van desde la aplicación tópica de flúor hasta tratamientos más invasivos, como la extracción de dientes y la rehabilitación ortodóncica. Es una enfermedad que afecta a pacientes desfavorecidos llegando a estadios severos cuando no se tratan, tiene etiología desconocida por parte de los padres donde no notan el desarrollo de los primeros signos clínicos, buscando atención dental tardía cuando el paciente presenta dolor y molestias al masticar en el lado afectado. Se ha observado que CPI tiene percusiones que afectan la calidad de vida y pueden comprometer el crecimiento y desarrollo 
del niño. La caries es, sin embargo, una enfermedad prevenible una vez que se conocen los factores que conducen a su desarrollo. Los hábitos alimentarios inadecuados son los principales factores de riesgo; la dieta del huésped puede considerarse el factor principal para determinar la susceptibilidad a la enfermedad. Se concluye que la caries dental (EC) es un deterioro dental fuertemente influenciado por el estilo de vida del individuo.

Palabras clave: Caries dental; Infância; Caries temprana.

\section{Introdução}

Entende-se como cárie dentária (CD), uma doença infecciosa, pós-eruptiva, transmissível, altamente influenciada pela dieta alimentar e que, quase sempre, é caracterizada por uma destruição progressiva e centrípeta dos tecidos mineralizados dos dentes. Fejerskov, e Kidd (2005) diz que a cárie dentária é uma doença multifatorial, que depende de quatro fatores principais (microbiota, hospedeiro, dieta e tempo), e não somente de um fator isolado.

É a doença crônica mais frequente na infância, que consiste em um grande problema de saúde pública mundial. É um fator importante e deve ser levado em consideração, pois pode ser prevenida, controlada ou revertida. Para sua prevenção, é necessário conhecer seus aspectos etiológicos e os fatores de risco relacionados ao seu desenvolvimento. O controle e a reversão de tal doença são possíveis caso seja diagnosticada em estágio inicial, que é a presença de mancha branca no esmalte dental, sem cavidades. Quando a situação clínica envolve cavidades dentárias, há necessidade de tratamento curativo e preventivo, a fim de modificar as condições que levaram ao seu desenvolvimento. Limeira, Lima, Franca, Colares, e Grinfeld (2010) concluem que é possível controlar a cárie através da implantação de programas educativos e/ou preventivos, não apenas para crianças, mas principalmente aos responsáveis por elas.

Segundo a American Academy of Pediatric Dentistry - AAPD (2010), Cárie Precoce da Infância (CPI), atualmente conhecida como Cárie da Primeira Infância, caracteriza-se pela existência de cárie (com cavidade ou não) em um ou mais dentes decíduos, restaurados/obturados, perdidos devido a CD ou restaurações, antes dos 71 meses de idade.

Hábitos alimentares inadequados, especificamente, após o primeiro ano de vida da criança, como o frequente consumo de açúcares e bebidas adoçadas, o aleitamento sob livre demanda e refeição noturna, e a falta de controle recorrente de biofilme, são os principais fatores de risco. Ribeiro, Oliveira e Rosenblatt (2005), dizem que os hábitos predisponentes ao surgimento de cáries são desacreditados pelo resultado de suas pesquisas. Os autores afirmam que a relação entre amamentação e CPI não foi significativa a presença de sacarose na mamadeira da maioria das crianças examinadas.

A família possui influência na definição de comportamentos de saúde oral e tem papel fundamental no desenvolvimento dos hábitos e dos conhecimentos da criança. Devem ser fornecidas informações sobre os fatores de cariogenecidade, alimentação e a importância de prevenir a CPI, aos pais das crianças (Ventura, 2016).

Assim, a CPI é uma lesão cariosa que atinge crianças na idade da pré-escola. É uma doença crônica e complexa que afeta a dentição decídua, porém ela pode ser prevenida e controlada. Cuidados específicos e diferenciados no tratamento e na prevenção favorecem a execução adequada de funções de digestão, fonação e respiração. Aspectos etiológicos e preventivos são de grande importância para o diagnóstico da cárie nesta fase precoce. Assim, essa revisão de literatura procura conhecer o desenvolvimento da cárie precoce, seus aspectos causadores, fatores de riscos, características presentes e formas de prevenção.

O objetivo deste estudo é descrever o perfil de saúde bucal em crianças, considerando que a CPI é um grave problema de caráter multifatorial, influenciada por hábitos deletérios de higiene bucal, microbiota, e dieta. Esta doença acomete os dentes decíduos precocemente, é de evolução rápida, podendo levar a sua total destruição.

\section{Metodologia}

Este estudo consiste de uma revisão narrativa de literatura, sendo coletados dados científicos, onde diante do tema foram selecionadas informações para melhor conhecimento dos impactos ocasionados pela doença, prevenção, controle e 
fatores de risco, além disso a doença afeta também a saúde geral, fala e autoestima. Para a pesquisa, foram utilizadas as bases de dados Google Acadêmico, SciELO, BVS e PubMed, com as seguintes palavras chave: Cárie dentaria, Infância, Cárie precoce, Dental caries, Childhood, Early caries. Foram selecionados artigos entre os anos de 1982 a 2021.

\section{Revisão de Literatura}

\subsection{Cárie da primeira infância}

A CD é uma doença crônica e infecciosa, pós erupção dentária e transmissível, de evolução rápida e severa que afeta grande quantidade de dentes decíduos. É definida por destruição progressiva e centrípeta dos tecidos mineralizados dos dentes, em consequência do desequilíbrio da mineralização e desmineralização do esmalte dental. A CD progride de forma lenta na maioria dos indivíduos, raramente é auto limitante e, na ausência de tratamento, progride até destruir totalmente a estrutura dentária (Fejerskov, \& Kidd, 2005).

Essa doença, tem se tornado um grande problema para saúde pública mundial, porém um fator que deve ser levado em consideração e é de grande importância, é que ela pode ser prevenida, controlada ou revertida, pois sua evolução pode causar grande destruição dos dentes, e até mesmo sua perda, resultando em complicações. Ribeiro, e Ribeiro (2004), com base no fato de que a cárie de estabelecimento precoce tem afetado crianças menores de três anos, a doença atualmente é considerada um problema de Saúde Pública.

A CPI é também definida como cárie de mamadeira, associada a hábitos alimentares inadequados principalmente no período noturno. O termo "cárie de mamadeira" e seus sinônimos "cárie de peito", "cárie de amamentação", síndrome da mamadeira noturna", atualmente, foram substituídos por CPI, denominação recomendada pelo Centro para o Controle e Prevenção de Doenças, em 1994 (Reisine, \& Douglass, 1998; Tinanoff, 1998; Weinstein, 1998).

Seu sinal clínico inicial se dá no esmalte dos dentes, por manchas brancas leves e opacas que podem progredir para extensas cavidades até a total destruição coronária (Losso, Tavares, Silva, \& Urban, 2009; Pineda, Osorio, \& Franzin, 2014).

A CPI é definida por uma ou mais superfícies cariadas, que apresenta ou não cavidade, perda dental ou superfícies dentais restauradas em qualquer dente decíduo em crianças menores de 6 anos de idade (American academy on pediatric dentistry dental care programs Committe, 2009; Drury et al., 1999).

\subsection{Etiologia da doença cárie}

A DC é de etiologia multifatorial, ocorrendo em virtude de uma mudança no equilíbrio homeostático da microbiota residente, devido ao crescimento de bactérias coriogênicas, que possuem capacidade de metabolizar o açúcar produzindo ácidos que, diminui o PH do dente promovendo a desmineralização do seu esmalte (Karpinski, \& Szkaradkiewicz, 2013; Kriger, \& Moysés, 1999; Leites, Pinto, \& Sousa, 2006; Lima, 2007; Melo, Azevedo, \& Henriques, 2008; Ribeiro, \& Ribeiro, 2004; Seow, 1998).

Após a ingestão da sacarose, inicia-se à glicolíase e ácidos são produzidos pelas bactérias presentes no biofilme dentário, que são capazes de desmineralizar a estrutura mineral dos dentes. Na interface placa-esmalte, ocorre aumento da concentração de íons hidrogênio, iniciando então a queda do PH no local e a formação da mancha branca, as quais sucessivos episódios de desmineralização causam o aparecimento de cavidades, iniciando a destruição do tecido da superfície dental (Karpinski, \& Szkaradkiewicz, 2013; Lima, 2007; Melo et al., 2008; Seow, 1998).

A CD tem origem bacteriana e apresenta caráter crônico. É definida pela destruição dos tecidos duros, devido a produção de ácido pela fermentação das bactérias que se aglomeram na superfície dentária (Fejerskov, \& Kidd, 2005; Karpinski, \& Szkaradkiewicz, 2013; Lima, 2007; Melo et al., 2008). 
Sempre que o açúcar for ingerido, as bactérias existentes no biofilme dentário irão produzir ácidos capazes de desmineralizar a estrutura dental a medida que o PH estiver baixo. Após algum tempo de exposição ao açúcar há a elevação do PH, e para que o esmalte-dentina e saliva consiga repor os minerais dissolvidos, ocorre a remineralização. A diminuição do PH deve ser interrompida tanto pela ação dos elementos-tampões fluídos da placa como pela saliva, antes que a lesão de cárie seja irreversível. Vale ressaltar, que o íon bicarbonato é o principal responsável pela capacidade - tampão, por ter sua concentração elevada aumentando o fluxo salivar contribuindo para o ganho de cálcio e potássio.

Ribeiro, e Ribeiro (2004), consideraram a cárie uma doença infectocontagiosa multifatorial, desencadeada por microorganismos cariogênicos, substrato cariogênico e hospedeiro suscetível. A saliva é o principal sistema de defesa do hospedeiro contra a cárie, remove alimentos e bactérias, mantém um sistema tampão contra os ácidos produzidos, age como um reservatório de cálcio e fosfato, necessários para a remineralização do esmalte.

\subsection{Fatores de riscos associados a cárie da primeira infância e suas particularidades}

O tampão salivar é responsável por neutralizar esses ácidos que aumentam à medida que o fluxo salivar se eleva, o qual se torna o fator mais importante na alteração da composição salivar (Losso et al., 2009; Ribeiro, \& Ribeiro, 2004).

Um fator de risco bastante importante para que ocorra a CD é a diminuição do fluxo salivar. Diariamente é secretado em torno de 700 a $800 \mathrm{ml}$ de saliva e a redução desse fluxo pode estar associada a medicamentos, portanto, deve-se ficar atento às causas medicamentosas e fisiológicas que possam provocar esse transtorno. Medicamentos que são utilizados por períodos longos de tempo, podem expor a cavidade oral a um nível maior de sacarose, devido à alta concentração deste açúcar nos medicamentos pediátricos, principalmente quando associado à uma higiene oral adequada não realizada após sua ingestão (Losso et al., 2009; Ribeiro, \& Ribeiro, 2004).

O baixo fluxo salivar por longo tempo causados por medicamentos ou não, podem trazer sérias consequências a cavidade bucal. A saliva tem suas funções protetoras devido aos elementos de sua composição, capacidade de destruição e neutralização de ácidos e a eliminação das substâncias cariogênicas conhecidas como "clearance salivar".

As glândulas secretam a saliva, e de acordo com Areias, Macho, e Guimarães (2010), “[...] desempenha funções protetoras através da capacidade de diluição e neutralização de ácidos e eliminação das substâncias com potencial cariogênico." (p.65).

A saliva tem ação protetiva contra a doença cárie por vários mecanismos. O esmalte tem superfície dura e não descamativa que, em contato com a saliva por alguns segundos absorve vários glicoproteínas ácidas (mucinas), essa membrana proteinácea e amorfa depositada sobre a superfície de hidroxiapatita compõe a película adquirida, as proteínas salivares absorvidas tornam-se insolúveis com o tempo (Braga, Mendes, \& Imparato, 2008).

A saliva possui capacidade tampão pela presença de íons de bicarbonato e fosfato que neutralizam os ácidos produzidos pelos microrganismos cariogênicos. Ela também tem a função de autolavagem e limpeza das superfícies dos dentes e possui ação antibacteriana por conter proteínas e imunoglobulinas que atuam contra os microrganismos cariogênicos (Braga et al., 2008).

A presença contínua de biofilme sobre os dentes e consumo diário de carboidratos fermentáveis podem causar a desmineralização das superfícies dentais, dessa forma a CPI depende da interação do biofilme e o açúcar, e caso não seja tratada ou revertida levará a criança a ter dificuldades de alimentação, dor, má oclusão e afetar a vida social.

Quando ocorre a perda precoce dos dentes decíduos, isto pode causar problemas como interferência na função mastigatória, a instalação de hábitos bucais deletérios, e portanto, na saúde física da criança, no fator estético, psicológico e ainda levar a problemas na fonação devido à função incorreta dos lábios e também da língua. Assim pode-se reabilitar a 
criança por meio da indicação de mantenedores funcionais removíveis (Cardoso, Lourenço Neto, Paschoal, Silva, \& Lima, 2011).

A lesão de cárie é a mesma, independente da dentição, em esmalte ou dentina seu desenvolvimento depende do acúmulo de biofilme dentário, da exposição frequente aos açúcares e do desequilíbrio entre des-remineralização da estrutura mineral dos dentes. O mineral do esmalte decíduo apresenta maior quantidade de carbonato sendo considerado um contaminante da hidroxiapatita que aumenta sua solubilidade, sendo assim, a lesão da cárie tem progressão mais rápida no dente decíduo do que no permanente, havendo rompimento da camada superficial da lesão de mancha branca, formando cavidades onde há progressão da perda mineral devido ao acúmulo de biofilme. A situação se torna mais grave quando a cavidade atinge a dentina, seu processo é rápido devido à menor espessura de esmalte em dentes decíduos.

O tratamento sintomático da cárie não interrompe a evolução da doença ao longo prazo. Ele pode evitar que a situação seja agravada e que ocorra complicações de ordem sistêmica, possibilitando conforto ao paciente. Porém tudo isso ocorrerá temporariamente (Corrêa-Faria, Martins-Júnior, Vieira-Andrade, Marques, \& Ramos-Jorge, 2013).

Assim, a CPI pode ser prevenida assim que forem detectados os fatores de riscos para seu surgimento e que conduzem vários agravos a saúde da criança. Crianças de 0 a 6 anos são considerados como grupo vulnerável por estarem expostos às interferências diretas dos cuidadores e, ainda constroem hábitos de dieta e higiene bucal que poderão permanecer no futuro da criança.

O tratamento da doença inicialmente, se dá de maneira preventiva, buscando educar e conscientizar os pais quanto aos hábitos alimentares, e principalmente sobre os hábitos de higienização oral, esclarecendo sobre sua importância (Corrêa- Faria et al., 2013).

Crianças que frequentam o consultório odontológico, com saúde bucal e que são conduzidas desde cedo (precocemente) ao serviço odontológico participam mais da abordagem preventiva do que da curativa, o que faz com que haja a redução da CPI.

Kuriakose e colaboradores (2015) observaram uma "relação entre um maior índice de CPI e visitas mais frequentes ao dentista, tal fato se justifica porque se observa que a procura por serviços odontológicos para crianças, em sua maioria, só ocorre quando existem problemas dentários que geram dor ou desconforto, já que a grande maioria da população não tem adequada formação em saúde bucal e detém de limitado acesso ao atendimento preventivo dos serviços públicos de saúde”. (p.69).

A dieta infantil também merece destaque em alguns aspectos como a amamentação, embora traz benefícios a saúde geral das crianças, a amamentação superior a 24 meses pode aumentar o risco em desenvolver lesões de cáries, pela exposição dos dentes aos carboidratos fermentáveis presente no leite materno. O uso de líquidos fermentáveis no período da noite, são hábitos prejudicais e em geral são os principais aliados aos agentes causadores da doença cárie (Corrêa-Faria et al., 2013).

Diante de estratégias preventivas na abordagem CPI, a Organização Mundial de Saúde e o Ministério da Saúde recomendam o aleitamento materno exclusivo nos primeiros seis meses. Quando a amamentação materna se prolonga, as crianças têm menos chances de serem precocemente apresentados a uma dieta cariogênica. O aleitamento noturno tem sido um dos principais responsáveis pela CPI infância. A CPI constitui-se de um tipo de CD rampante, associada a hábitos alimentares inadequados durante o processo de desmame (Johnsen, 1982; Milnes, 1986).

Atribuiu-se ao fato de que haja menos movimentos de autolimpeza e fluxo salivar durante a noite, com isso há menos capacidade de neutralização de ácidos, provocando a estagnação do leite na boca por longos períodos e exposição dos dentes aos carboidratos fermentáveis. Tem-se afirmado que crianças de 0 a 6 anos de idade não percebem a importância da escovação, não tendo facilidade para uma permanente remoção do biofilme dentário, diante disso é necessário que a criança tenha assistência e seja orientada para que haja redução dos riscos de desenvolvimento da CPI. Sobre às características clínicas, 
Martins et al. (1998) relataram que ao realizar o exame clinico da criança em estágio inicial, pode haver o surgimento de manchas brancas próximo a margem gengival, e que o não interrompimento dessas lesões evoluem para cavitações.

\subsection{Salientar os primeiros sinais da doença cárie e complicações inerentes}

A CPI ou também chamada de cárie de mamadeira, acontece na primeira infância, é caracterizada por lesões de CD em crianças menores que 6 anos de idade. O fator que leva ao seu aparecimento mais comum é o uso de mamadeiras com líquidos fermentáveis, geralmente durante o período da noite. Vitaminas, xaropes, leites, sucos e alimentos açucarados no geral constituem agentes responsáveis diretos pela doença (Losso et al., 2009).

É uma instabilidade que afeta a dentição decídua de crianças na idade de pré-escola, é uma erupção dentária que se inicia com o surgimento de manchas brancas ou opacas e que reduz de imediato, depois da erupção dentária é definida como cárie na dentição decídua a qual seus estágios são classificados em: leve quando há o surgimento da cárie em pelo menos um dos incisivos superiores ou primeiros molares superiores, moderada quando ocorre o surgimento da cárie na superfície vestibular de um dos dois primeiros molares inferiores e severa quando há o envolvimento de múltiplas superfícies dentária, com a evolução da doença surgem cavidades com perda da estrutura dental podendo levar a destruição do dente, estágio o qual acomete a dentina e áreas cavitadas (Miyata, Bonini, Calvo \& Politano, 2014).

Desta forma, o termo CPI abrange de forma mais adequada a doença que acomete bebês e crianças em idade préescolar, proporcionando uma visão ampla da real situação clínica e das variadas opções de tratamento, como restaurações diretas com resina composta, endodontia, coroas de aço facetadas, até mesmo a exodontia dos dentes acometidos (Miyata $e t$ al., 2014).

Com a evolução da criança a doença tende a expandir sua severidade, podendo causar desde lesões de manchas brancas a visíveis lesões cariosas, afetando negativamente a qualidade de vida das crianças acometidas. Segundo Losso et al., (2009), inicialmente o aspecto clínico da doença é a presença de manchas brancas e opacas em terço cervical, que são áreas desmineralizadas pela presença de biofilme dental, progredindo para uma cor amarronzada ou enegrecida e, em casos avançados, pode ocorrer fraturas nas coroas dos dentes na margem gengival.

A lesão cariosa se forma somente quando o resultado cumulativo de des-remineralização acarreta a perda mineral e nem sempre são visíveis, no início do seu processo se desenvolvem de forma lenta e se tornam visíveis através da opacidade localizada nas faces dentais onde ocorre a acumulação de biofilme, e quando não paralisada a superfície da lesão fraturada gera cavidade no dente. A mancha branca no dente é a primeira manifestação da cárie, é percebida quando realizamos a secagem da superfície. Quando a lesão se torna visível com a superfície úmida, certamente ela já chegou em dentina (Leão Filho, \& Souza, 2011).

A CD é também definida como uma lesão causada por bactérias que perfuram o dente causando sintomas de dor e desconforto levando as crianças acometidas a terem o risco de problemas nas superfícies dos dentes, dificuldades em alimentar-se, comprometimento no desenvolvimento da criança, baixo peso e estrutura. Normalmente aparecem em áreas onde há a estagnação e retenção do biofilme dental, nas oclusais (sulcos e fóssulas) e nas proximais, sendo lento sua evolução de desmineralização inicial até à cavitação. Portanto, as CDI se manifestam de progressiva e em cascata, nos incisivos superiores, imediatamente após a erupção, e as superfícies lisas de molares decíduos e caninos (Areias et al., 2010; Cosme, \& Marques, 2005; Pereira, 2001; Silva, Basso, \& Locks, 2010).

A sensibilidade no dente com a lesão cárie pode surgir desde a uma simples mudança de temperatura, com alimentos quentes ou frios ou com um simples toque no dente cariado, devido ao aumento da sensibilidade e dores pela própria lesão, que aumentam aos poucos gerando desconforto na hora de mastigar os alimentos, brincar e dormir (American Dental Association, 
2013; Areias et al., 2010; Arora et al., 2011; Boj et al., 2005; Cosme, \& Marques, 2005; Losso et al., 2009; Palma, García, \& Gonzáles, 2009; Pereira, 2001; Silva et al., 2010)

A presença da dor de dente é um sintoma comum das lesões cariosas não tratadas ou em estágios severos, em muitos casos as cáries atingem regiões próximas aos nervos dentais, causando desconforto que pode ser constante, variando a intensidade (leve/moderada/intensa) afetando significativamente a qualidade de vida da criança que passa a ter dificuldades para se alimentar, podendo gerar má nutrição. Tal condição, quando prolongada, pode afetar o desenvolvimento e crescimento físico e intelectual, diminuindo capacidade de aprendizagem (American Dental Association, 2013; Arora., et al., 2011; Cosme, \& Marques, 2005; Losso et al., 2009; Palma et al., 2009; Pereira, 2001; Silva et al., 2010)

Perdas extensas de estrutura dental em dentes decíduos, principalmente em dentes anteriores que são os mais acometidos nos primeiros anos de vida causam alterações estéticas e influenciam nas atividades sociais das crianças inclusive com repercussões psicológicas e alterações fonéticas. A perda prematura dos dentes causa imperfeição no desenvolvimento da fonética e má articulação da linguagem, afetando sons como o "V”, "S", "F” e o “Z” (Boj et al., 2005).

Infecções dentárias graves, como abcessos podem comprometer a saúde sistémica da criança, perdas dentárias podem ocasionar maloclusão e impactos na formação das arcadas dentárias, quando as cáries não são tratadas, a tendência é de que as bactérias atinjam a polpa do dente, região que se estende até a raiz e é composta pelos nervos e vasos sanguíneos do dente, isso faz com que ocorra inchaços, inflamações e até sangramento na gengiva durante a escovação podendo levar a perda do dente. A perda precoce dos decíduos leva à frequente deslocamento dos dentes adjacentes, criando um desequilíbrio entre os antagonistas, redução de espaço para erupção dos permanentes, impactações dentárias, mordidas cruzadas, desvios da linha média e erupções ectópicas (Boj et al., 2005; Cosme, \& Marques, 2005; Losso et al., 2009; Pereira, 2001; Silva et al., 2010).

\subsection{Apresentar aspectos etiológicos e preventivos proporcionando uma melhora na saúde bucal}

A CPI, como já mencionado, acomete bebês e crianças de idade pré-escolar, e se desenvolve logo após a erupção dentária. A saúde bucal é um direito básico do ser humano sendo determinante para uma boa qualidade de vida (Petersen, 2003).

A busca pela melhoria da saúde oral deve estar centrado em diagnósticos precisos, onde o tratamento da doença visa estabelecer o equilíbrio e a saúde bucal do paciente por meio do controle dos fatores etiológicos, como remoção do biofilme, ações educativas conduzidas por odontólogos, educadores, instrução de higiene, dieta e aplicação de fluoretos. A saúde bucal é pré-requisito da saúde corporal, sendo prioritário no bem-estar e determinante para a qualidade de vida (Casals, \& García Pereiro, 2014).

A CD é mediada por fatores primários e fatores secundários, que durante a anamnese devem ser diagnosticados, e ainda classificados, de alguma maneira, o risco e atividade da doença na criança e na mãe para que a partir daí o indivíduo possa modificar seus hábitos alimentares e de higienização. Para a ocorrência da CD os fatores primários são essenciais (ambiente, hospedeiro e agente), os fatores secundários podem influenciar na evolução das lesões (predisposição genética, a presença de flúor na cavidade bucal, a higiene bucal, o estatuto socioeconômico, o estado de saúde geral) (Melo et al., 2008).

As interações entre tais fatores podem aumentar ou diminuir a resistência do hospedeiro, o potencial cariogênico da microbiota e ainda, a cariogenecidade do substrato (dieta) (Melo et al., 2008).

Métodos de prevenção da CPI crônica se inicia na gestação. A consulta odontológica é de grande importância para que seja avaliada a condição bucal da mãe, para que possa estabelecer um tratamento curativo ou preventivo para os cuidados bucais afim de controlar os níveis de Streptococcus mutans e, dessa forma diminuir a transmissão de bactérias cariogênicas para seus bebês. Quanto mais cedo ocorre a infecção das crianças por Streptococcus mutans, maior é a possibilidade do 
aparecimento de cáries (Fontana et al., 2009; Gussy, Waters, Walsh, \& Kilpatrick, 2006; Pereira, 2001), ou a predisposição destas na dentição permanente (Berkowitz, 2003; Palma et al., 2009; Seow, 1998).

A prevenção da cárie precoce na infância é amplamente divulgada, profissionais de odontologia têm lançado alertas sobre a necessidade de aceitação de medidas preventivas que objetivam o controle e o reconhecimento prematuro da análise da causa e sintoma, é de fundamental importância o controle de doenças infecciosas e da dieta materna, desta forma a prevenção da cárie prematura na infância deve ter início na gestação (Plonka et al., 2012).

Portanto, o sucesso na prevenção depende do bloqueio ou postergação da transmissão de Streptococcus mutans, e a conscientização da necessidade constante de higiene bucal (Arora et al., 2011). Existem agentes que contribuem para a diminuição destes microorganismos na cavidade oral (xilitol, verniz fluoretado e verniz de clorexidina) (Plonka et al., 2012).

A prevenção primária da CPI e controle de contaminação inicia-se nos cuidados pré-natais com a determinação dos níveis de Streptococcus mutans na gestante, tratamento de lesões cavitárias e colocação de selantes e fissuras, informações sobre o meio de transferência das bactérias para o filho (chupeta, chávena, beijo etc.), aconselhamento de práticas de higiene oral entre outros.

A American Academy of Pediatric Dentistry (AAPD) (2010) sugere que a prevenção da CD inicia-se com a conscientização da gestante, tanto com os cuidados de higiene, como de dieta, como ainda no acompanhamento do bebê no consultório odontológico, não devendo a primeira consulta postergar para além dos 6 meses de vida da criança, sendo crucial com a erupção do primeiro dente.

A CD é um processo pelo qual envolve perda de minerais, é um processo de decomposição que pode ser prevenido, trabalhando de perto com um profissional da odontologia e acompanhada pelas indicações e recomendações desse profissional, para ajudar na prevenção da CD, deve se limitar a ingestão de açúcares, alimentos grudentos e bebidas açucaradas entre as refeições, uma forma de prevenir sulcos, fossas e fissuras em alguns dentes é fazer com que a parte afetada do dente seja recoberta por uma camada de material plástico selante, que ao endurecer agem como barreira protegendo a superfície dos dentes da placa bacteriana e ácidos, o selante é uma substância a qual apresenta eficácia de escoamento nas cicatrículas e fissuras do dente, é proposto como tratamento preventivo em molares decíduos e permanentes que apresentam fossas e fissuras profundas de difícil higienização (Ventura, 2016).

Os selantes são medidas eficazes na prevenção de cáries de fóssulas e fissuras dos dentes, que atinge maior parte das cáries em todos os números etários, apresentando vantagens como o baixo custo, a facilidade de colocação, a eficácia e o riscos de lesão iatrogênica (Ventura, 2016).

O flúor também tem papel fundamental na prevenção do deterioramento dental, protege os dentes das cáries e bactérias podendo ajudar a manter a boca limpa e saudável, uma das melhores formas de prevenir a perda mineral dos dentes ou desmineralização e remineralização é usar uma pasta dental contendo flúor, o flúor tem diversas formas de uso, e é preconizado como método profilático da CD.

O flúor se caracteriza como uma defesa de grande importância na redução da prevalência e gravidade de CD (Arora $e t$ al., 2011; Sassetti, 2002). Sassetti (2002) diz que sua ação terapêutica e preventiva é tópica e pós-eruptiva e que o uso de dentífricios fluoretados é uma excelente forma de obter o efeito tópico.

O flúor impede a desmineralização da superfície dentária, estimulando sua remineralização e interfere impedindo o metabolismo bacteriano (Arora et al., 2011; Casals, \& García Pereiro, 2014; Pereira, 2001).

\subsection{Descrever a cárie e todos os seus aspectos para promover ações de promoções em saúde bucal}

Descrita inicialmente na literatura em 1934, a CD tem seu vocábulo derivado do latim que inicialmente foi usado para descrever "buracos" nos dentes, sem conhecimento aprofundado tanto na patogênese da doença como na etiologia, contudo, 
hoje é definida como uma doença infecto contagiosa, desencadeada por microorganismos, marcada por uma alteração ecológica e/ou metabólica no biofilme dentário, ocasionada pela exposição a carboidratos alimentares fermentáveis, onde ocorre alterações de microorganismos da doença. Então, é uma doença de longa duração, causada pela desmineralização da superfície do dente por ácidos procedente da fermentação dos hidratos de carbono da dieta, pelas bactérias e pelo tempo (Karpinski, \& Szkaradkiewicz, 2013; Kriger, \& Moysés, 1999; Leites et al., 2006; Lima, 2007; Melo et al., 2008; Seow, 1998).

A CD é caracterizada por uma doença crônica e multifatorial, apresenta perda de minerais (desmineralização) e ganho de minerais (remineralização) nos tecidos mineralizados dos dentes, a desmineralização dental caracteriza-se pela perda de cálcio do dente, este mineral que o constitui, é responsável por dar dureza na camada mais externa do dente ou seja, o esmalte dentário (Lima, 2007).

A susceptibilidade do dente à cárie é definida pelo grau da mineralização do esmalte, o que torna uma alternância de maior ou menor resistência à dissolução ácida, cuja mineralização é conduzida por fatores intrínsecos que ocorrem durante a formação do dente e os extrínsecos, que são fatores locais e ambientais (Lima, 2007).

A desmineralização do esmalte do dente leva a constituição da mancha branca ativa, a qual é a primeira manifestação clínica visível, dessa maneira, é possível compreender a importância de visitas regulares ao dentista pois irá contribuir para iniciar o tratamento desde o início, antes que a evolução do processo de desmineralização da mancha branca se transforme em uma cárie, os resíduos de alimentos que permanecem por longo tempo na cavidade bucal influenciam na ação de bactérias que diminuem o cálcio da estrutura dentária, a qual contribui para a formação da cárie, a má higienização bucal também tem se tornado um grande problema (Melo et al., 2008).

Sua identificação prematura, poderá possibilitar a intervenção e reversão da situação, evitando a perda do dente. Sendo assim, a CPI Grave pode ser diagnosticada desde o aparecimento do primeiro dente. O primeiro sinal é a desmineralização ou a presença de cavidade em qualquer dente. O diagnóstico precoce, é de grande importância para a abordagem da criança, e também a nível epidemiológico, para posterior organização de ações de promoção à saúde oral, na saúde pública. Sobre a CPI Grave, esta tem progressão rápida, o que resulta na destruição das coroas dos dentes anteriores em um período curto de tempo (Melo et al., 2008).

É de essencial importância, a realização de exame oral detalhado e avaliação cuidadosa em cada consulta para o monitoramento da evolução e risco da cárie no paciente. O diagnóstico da cárie tem se baseado em técnicas básicas como exame visual e de translucidez do dente, se necessário exame clínico com sonda clínica e exame radiográfico, juntamente com a inspeção visual das superfícies dentárias, sendo importante uma boa fonte de luz, com a limpeza e secagem prévia das peças dentárias (Casals, \& García Pereiro, 2014; Leão Filho, \& Souza, 2011).

Ao realizar a inspeção visual, a superfície dentária deve estar totalmente limpa, sem biofilme, restos de alimento ou qualquer outro fator que impeça a visualização da superfície do dente (Casals, \& García Pereiro, 2014; Leão Filho, \& Souza, 2011). Através do aspecto visual do dente podemos obter informações sobre as lesões de cáries como estrias pigmentadas, escurecidas ou sombras acinzentadas sob o esmalte (Bird, \& Robinson, 2012).

A CD é uma forma de deteriorização do dente, que é fortemente influenciada pelo estilo de vida do indivíduo, resultante da ação de determinadas bactérias presentes na boca que caso não haja uma intervenção adequada poderá levar à perda do dente afetado. Pode ocorrer desde a idade precoce até a idade geriátrica, podendo ser identificada em diferentes fases: a fase inicial quando ainda está superficial, a avançada quando está mais profunda e pode atingir o nervo do dente e até causar infecção, a cárie coronária é aquela que ocorre na coroa do dente, a cárie radicular ocorre quando a raiz do dente já está exposta por retração da gengiva, a cárie cervical está na zona de transição da coroa para a raiz do dente, características destrutivas de cárie, atinge a idade precoce em alta prevalência levando em consideração uma atenção especial (Gussy et al., 2006). 
As lesões de cariosas tem se tornado mais graves com o aumento da idade, levando-o a criança a ter dor, problemas oclusais, formação de abcessos, dificuldades com a alimentação, comprometimento do crescimento, prejuízo estético e déficit de atenção (Gussy et al., 2006).

A CD também pode ocorrer por contágio ou transmissão, é infectocontagiosa e pode se propagar pela contaminação por bactérias cariogênicas podendo ser adquiridas pelo contato direto ou indireto que resulta ao aparecimento da lesão de CPI. O contato direto é normalmente através do beijo, entre pais e bebês que é transmitida pela saliva, o contato indireto se dá através de objetos que estão contaminados com saliva por consequência de bactérias como copos, talheres, brinquedos, até ao soprar a comida do bebê para esfriar. A contaminação é adquirida através do contato físico, e efetuada por meio da saliva, contato direto por meio de beijos, mãos ou pele contaminadas, habito da criança levar a mão dentro da boca da mãe e, eventualmente, de volta para sua boca ou de alimentos manuseados por indivíduos contaminados (Freire, Fragoso, Grinfeld, \& Maciel, 2004; Sakai et al., 2008).

Por ser uma doença que provoca a destruição dos tecidos dentários, é diagnosticada clinicamente em estágios iniciais (lesões em esmalte) ou em estágios mais tardios (cavitação em dentina ou necrose da polpa dentária), durante a detecção da doença cárie é de grande importância avaliar a atividade dela, se é ativa ou inativa, o tratamento da doença cárie possui condição de equilíbrio e saúde bucal do paciente por meio de controle de fatores etiológicos, e ações de promoção a saúde bucal devem inserir na estratégia planejada pela equipe de saúde avaliando as características do perfil epidemiológico da população, quanto as condições socioeconômicas, hábitos de higiene, estilo de vida e necessidades de saúde, essas ações de proteção à saúde podem ser desenvolvidas a nível individual ou coletivo. Volpato, e Figueiredo (2005), relataram que em programas de educação para prevenção da cárie em crianças, os pais são convidados a auxiliar seus filhos na escovação e na fixação do aprendizado em ambiente familiar, uma vez que são educadores incentivadores importantíssimos na formação de hábitos de higiene de seus filhos.

A estimulação da higiene bucal na população socioeconomicamente mais baixo, por meio da educação tem se tornado um meio de transformação social, onde reformula hábitos de higiene, melhora na autoestima, portanto a comunicação verbal tem se tornado um meio simples e direto para uma modificação satisfatória no comportamento do indivíduo em relação ao controle do biofilme. Volpato, e Figueiredo (2005), descreveram que os fatores comportamentais que determinam má higiene oral também podem contribuir para estabelecimento do consumo inadequado de alimentos cariogênicos. A comunicação verbal é um meio simples e direto para modificar o comportamento do indivíduo e leva-lo a exercer um controle satisfatório do biofilme dental.

\section{Discussão}

A cárie rampante ou CPI tem alto índice de prevalência, especialmente em áreas onde as pessoas tem menos poder aquisitivo e pouco acesso à informação sobre a importância da higienização bucal tanto em bebês quanto em crianças.

É uma patologia que tem se apresentado altamente destrutiva e debilitante, apresenta em geral estágios avançados causando sérios prejuízos a estética, fonação, deglutição e alimentação da criança, devido a perda coronária dos elementos dentários decíduos. A cárie rampante traz como consequência, grandes destruições dentárias com prejuízos à estética, alteração de funções da fonação, por envolver dentes anteriores e mastigação, perda da dimensão vertical e danos psicológicos, devido à destruição parcial ou total da dentição decídua (Pineda et al., 2014).

A prevenção da CPI tem sido largamente publicada na comunidade odontológica e também em programas voltados para a promoção de saúde bucal, profissionais de odontologia tem lançado alertas sobre a necessidade da adoção de medidas preventivas executadas que objetivam o controle e o diagnóstico precoce da patologia como intervenções junto aos pais ou 
responsáveis pela criança. A integração dos pais ao tratamento é essencial, visto que eles são responsáveis pelos cuidados caseiros quanto à saúde bucal e proporcionam os meios adequados para mudanças de hábitos alimentares e de higiene objetivando a promoção de saúde (Martins et al., 1998).

O tratamento requer profissional altamente habilitado, e sendo de alto custo e difícil acesso. A CPI causa, dessa forma, graves danos à saúde do paciente, ou seja, ao seu bem-estar biopsicossocial (Chaves, Freitas, \& Colares, 2001).

\section{Considerações Finais}

Perante o que foi apresentado neste estudo, conclui-se que a CPI por ser uma doença infecto contagiosa e transmissível constitui-se em um problema que pode gerar graves complicações, que comprometem a qualidade de vida das crianças, tanto na saúde geral, social e psicológica. Considerando todos os fatores de riscos, não é possível avaliar quais dentre eles exercem maior ou menor influência da cárie, somado a esses fatores as condições socioeconômicas dos pais dessa forma, torna-se de extrema necessidade programas educativos e preventivos, para promover a saúde oral infantil, a conscientização dos pais é imprescindível para prevenção da CPI.

\section{Referências}

American Academy of Pediatric Dentistry. (2010). Policy on the use of xylitol in caries prevention. REFERENCE MANUAL, 32 (6). https://scholar.google.com.br/scholar?q=Policy+in+the+use+of+xylitol+in+caries+prevention\&hl=pt-BR\&as_sdt=0\&as_vis=1\&oi=scholart.

American Academy On Pediatric Dentistry Dental Care Programs Committe. (2009). Policy on oral health care programs for infants, children, and adolescents. Pediatr Dent, 30 (7).

American Dental Association. (2013). Baby bottle tooth decay (early childhood caries). Patient Smart-Patient Education Center.

Areias, C. M., Macho, V., \& Guimarães, H. (2010). Cárie precoce da infância - O estado da arte. Acta Pediatr Port, 41 (5), 217-21. https://www.researchgate.net/publication/231168082_Caries_precoces_da_infancia_-_o_estado_da_arte.

Arora, A. et al. (2011). Early childhood feeding practices and dental caries in preschool children: a multi-centre birth cohort study. BMC Public Health, 11 (28). https://pubmed.ncbi.nlm.nih.gov/21223601/.

Berkowitz, R. J. (2003). Causes, treatment and prevention of early childhood caries: a microbiologic perspective. J Can Dent Assoc, 69 (5), 304-307. https://pubmed.ncbi.nlm.nih.gov/12734024/.

Bird, D. L., \& Robinson, D. S. (2012). Fundamentos em odontologia para TSB e ASB. 10ª edição. Rio de Janeiro: Elsevier. https://vdocuments.com.br/birdfundamentos-em-odontologia-para-tsb-e-asb-10a-edicao.html.

Boj, J. R. et al. (2005). Dentista pediátrico. Barcelona: Masson.

Braga, M. M., Mendes, F. M., \& Imparato, J. C. P. (2008). A doença Cárie Dentária. In: IMPARATO, J. C. P.; RAGGIO, D. P.; MENDES, F. M. Selantes de fossas e fissuras: quando como e por quê? São Paulo: Livraria Santos Editora.

Cardoso, C. A. B., Lourenço Neto, N., Paschoal, M. A. B., Silva, S. M. B. da, \& Lima, J. E. O. (2011). Reabilitação bucal na primeira infância: relato de caso. Revista Odontológica de Araçatuba, 32 (2), 49-53. https://pesquisa.bvsalud.org/portal/resource/pt/bbo-41644.

Casals, P. E., \& García Pereiro, M. A. (2014). Para la prevención y tratamiento no invasivo de la caries dental. Guía de práctica clínica. RCOE, 19 (3), 189248. http://diposit.ub.edu/dspace/bitstream/2445/66926/1/654149.pdf.

Chaves H. C. B., Freitas, R.L., Colares, V. (2001). Perfil psicosocial dos responsáveis por pré-escolares portadores de cárie de mamadeira da cidade de Recife. In: Anais da Faculdade de Odontologia da Universidade Federal de Pernambuco. Recife. UFPE, 31-37.

Corrêa-Faria, P., Martins-Júnior, P. A., Vieira-Andrade, R. G., Marques, L. S., \& Ramos-Jorge, M. L. (2013). Factors associated with the development of early childhood caries among Brazilian preschoolers. Brazilian Oral Research, 27 (4). https://www.scielo.br/j/bor/a/szQ6DSLwrcRpnWJcr7vdrML/?lang=en.

Cosme, P., \& Marques, P. F. (2005). Cáries precoces de infância - Uma revisão bibliográfica. Revista Portuguesa de Estomatologia, Medicina Dentária e Cirurgia Maxilofacial, 46 (2). https://www.spemd.pt/imagens/anexo_294.pdf.

Drury, T. F. et al. (1999). Diagnosing and reporting early childhood caries for research purposes. A report of a workshop sponsored by the National Institute of Dental and Craniofacial Research, the Health Resources and Services Administration, and the Health Care Financing Administration. J Public Health Dent., 59 (3), 192-197. https://pubmed.ncbi.nlm.nih.gov/10649591/.

Fejerskov, O., \& Kidd, E. (2005). Cárie dentária: a doença e seu tratamento clínico. São Paulo: Santos. 
Fontana, M. et al. (2009). Xylitol: effects on the acquisition of cariogenic species in infants. Pediatr Dent., 31 (3), 257-266. https://pubmed.ncbi.nlm.nih.gov/19552232/.

Freire, A. P. L., Fragoso, J. L., Grinfeld, S., \& Maciel, M. A. V. (2004). Existe contaminação de estreptococos do grupo mutans na saliva das chupetas de crianças portadoras deste hábito de sucção? Estudo em crianças na faixa etária de 06 a 09 meses em creches na rede pública da cidade do Recife - PE. International Journal of Dentistry, 3 (2), 361-366. https://periodicos.ufpe.br/revistas/dentistry/article/viewFile/13837/16686.

Gussy, M. G., Waters, E. G., Walsh, O., \& Kilpatrick, N. M. (2006). Early childhood caries: Current evidence for aetiology and prevention. J Paediatr Child Health, 42 (1-2), 37-43. https://pubmed.ncbi.nlm.nih.gov/16487388/.

Johnsen, D. C. (1982). Characteristics and backgrounds of children with "nursing caries". Pediatr Dent., 4 (3), 218-24. https://pubmed.ncbi.nlm.nih.gov/6963401/.

Karpinski, T. M., \& Szkaradkiewicz, A. K. (2013). Microbiology of dental caries. J Biol Earth Sci, 3 (1).

Kriger, L., \& Moysés, S. T. (1999). A filosofia de promoção de saúde na clínica privada. In: KRIGER, L (coord.). Promoção de saúde bucal. 2 ed. São Paulo: Artes Médicas.

Kuriakose, S., Prasannan, M., Remya, K. C., Kurian, J., \& Sreejith, K. R. (2015). Prevalence of early childhood caries among preschool children in Trivandrum and its association with various risk factors. Contemp Clin

Dent., 6 (1), 69-73. https://pubmed.ncbi.nlm.nih.gov/25684915/.

Leão Filho, J. C. B., \& Souza, T. R. (2011). Métodos de detecção de cárie: do tradicional às novas tecnologias de emprego clínico. Revista de Odontologia da Universidade Cidade de São Paulo, 23 (3), 253-265. https://publicacoes.unicid.edu.br/index.php/revistadaodontologia/article/view/385/280.

Leites, A. C. B. R., Pinto, M. B., \& Sousa, E. R. de. (2006). Aspectos microbiológicos da cárie dental. Rev Salusvita, 25 (2), 135-148. https://pesquisa.bvsalud.org/portal/resource/pt/lil-558472.

Lima, J. E. O. (2007). Cárie dentária: um novo conceito. Rev. Dent. Press Ortodon. Ortop. Facial, 12 (6). https://www.scielo.br/j/dpress/a/4G4SMnBnHzyvvbFNqVK9DWL/abstract/?lang=pt.

Limeira, A. B., Lima, F. R. S. B., Franca, C., Colares, V., \& Grinfeld, S. (2010). Prevalência de cáries em crianças e cuidadores de uma creche em Recife/PE. Odontol. Clín.-Cient, Recife, 9 (4). http://revodonto.bvsalud.org/scielo.php?pid=S1677-38882010000400010\&script=sci_arttext.

Losso, E. M., Tavares, M. C. R., Silva, J. Y. B. da, \& Urban, C. A. (2009). Severe early childhood caries: an integral approach. J Pediatr., Rio de Janeiro, 85 (4), 295-300. https://pubmed.ncbi.nlm.nih.gov/19668905/.

Martins, A. L. C. et al. (1998). A cárie dentária. In: Corrêa MSNP. Odontopediatria na primeira infância. São Paulo: Santos, 195-208.

Melo, P., Azevedo, Á., \& Henriques, M. (2008). Cárie dentária - a doença antes da cavidade. Acta Pediatr Port, 39 (6), 253-259. https://pjp.spp.pt/article/view/4616.

Milnes, A. R. (1986). Nursing caries - etiology and treatment. In: Levine N. Current treatment in dental practice. Toronto: WB Saunders, 446-52.

Miyata, L. B., Bonini, G. C., Calvo, A. F. B., \& Politano, G. T. (2014). Reabilitação estética e funcional em paciente com cárie severa da infância: relato de caso. Rev. Assoc. Paul. Cir. Dent., 68 (1), 22-9. http://revodonto.bvsalud.org/scielo.php?pid=S0004-52762014000100003\&script=sci_arttext\&tlng=pt.

Palma, C., García, C., \& González, Y. (2009). Prevenció de càries dental en infants menors de 3 anys. Pediatria Catalana, 69 (4), 200-205. http://webs.academia.cat/revistes_elect/view_document.php?tpd=2\&i=2054.

Pereira, A. (2001). Cáries precoces da infância. Porto, ed. Medisa.

Petersen, P.E. (2003). The World Oral Health Report 2003: continuous improvement of oral health in the 21st century--the approach of the WHO Global Oral Health Programme. Community Dent Oral Epidemiol. $31 \quad$ (1), 3-23. doi: 10.1046/j..2003.com122.x. PMID: 15015736. https://pubmed.ncbi.nlm.nih.gov/15015736/.

Pineda, I. C., Osorio, S. R. G., \& Franzin, L. C. S. (2014). Cárie precoce da primeira infância e reabilitação em odontopediatria. Revista Uningá Review, 19 (3). http://revista.uninga.br/index.php/uningareviews/article/view/1543.

Plonka, K. A. et al. (2012). A longitudinal study comparing mutans streptococci and lactobacilli colonisation in dentate children aged 6 to 24 months. Caries Res, 46 (4), 385-393. https://pubmed.ncbi.nlm.nih.gov/22699390/.

Reisine, S., \& Douglass, J. M. (1998). Psychosocial and behavioral issues in early childhood caries. Community Dent Oral Epidemiol., 26 (1), $32-44$. https://pubmed.ncbi.nlm.nih.gov/9671198/.

Ribeiro, A. G., Oliveira, A. F., \& Rosenblatt, A. (2005). Cárie precoce na infância: prevalência e fatores de risco em pré-escolares, aos 48 meses, na cidade de João Pessoa, Paraíba, Brasil. Cad. Saúde Pública, Rio de Janeiro, 21 (6), 1695-1700. https://www.scielo.br/j/csp/a/GZdbQLfzPHvhyWcqGPfzQ3N/abstract/?lang=pt.

Ribeiro, N. M. E., \& Ribeiro M. A. S. (2004). Aleitamento materno e cárie do lactente e do pré-escolar: uma revisão critica. J. Pediatr., Rio de Janeiro, 8 (5). https://www.scielo.br/j/jped/a/W3hN3SYNFdsPjyrkfxpC7yp/abstract/?lang=pt.

Sakai, V. T. et al. (2008). Knowledge and attitude of parents or caretakers regarding transmissibility of caries disease. J Appl Oral Sci, 16 (2), 150-154. https://pubmed.ncbi.nlm.nih.gov/19089208/. 
Research, Society and Development, v. 10, n. 14, e268101422093, 2021

(CC BY 4.0) | ISSN 2525-3409 | DOI: http://dx.doi.org/10.33448/rsd-v10i14.22093

Sassetti, L. (2002). Saúde Infantil e Juvenil: Programa Tipo de Actuação / Direcção-Geral da Saúde. 2a edição. Lisboa: Direcção-Geral da Saúde. https://www.mgfamiliar.net/itemgenerico/saude-infantil-e-juvenil-programa-tipo-de-actuacao/.

Seow, W. K. (1998). Biological mechanisms of early childhood caries. Community Dent Oral Epidemiol, 26 (1), 8-27. https://pubmed.ncbi.nlm.nih.gov/9671196/.

Silva, C. M., Basso, D. F., \& Locks, A. (2010). Alimentação na primeira infância: abordagem para a promoção da saúde bucal. Rev Sul-Brasil Odontol., 7 (4), 458-465. http://revodonto.bvsalud.org/scielo.php?pid=S1984-56852010000400013\&script=sci_arttext.

Tinanoff, N. (1998). Introduction to early childhood caries conference: initial description and current understanding. Community Dent Oral Epidemiol., 26 (1), 5-7. https://pubmed.ncbi.nlm.nih.gov/9671195/.

Ventura, S. P. F. (2016). A influência dos hábitos parentais no aparecimento de Cárie Precoce da Infância grave. Dissertação apresentada à Universidade Fernando Pessoa como parte dos requisitos para obtenção do grau de Mestre em Medicina Dentária, Universidade Fernando Pessoa, Porto. http://docplayer.com.br/88082465-A-influencia-dos-habitos-parentais-no-aparecimento-de-carie-precoce-da-infancia-grave.html.

Volpato, L. E. R., \& Figueiredo, A. F. (2005). Estudo da clientela do programa de atendimento odontológico precoce em um serviço público do município de Cuiabá, Mato Grosso. Rev. bras. saúde matern. infant., 5 (1), 45-52. https://pesquisa.bvsalud.org/portal/resource/pt/lil-399758.

Weinstein, P. (1998). Public health issues in early childhood caries. Community Dent Oral Epidemiol., 26 (1), 84-90. https://pubmed.ncbi.nlm.nih.gov/9671204/. 